simply, since the potential function for displacements perpendicular to the axis of the $\mathrm{C}_{2} \mathrm{H}_{2}$ molecule is rather more complicated, and in fact the bands found by Randall and Barker will have to be employed in order to determine it.

G. B. B. M. Sutherland.

Laboratory of Physical Chemistry, Cambridge.

Oct. 20 .

1 H. M. Randall and E. F. Barker, Phys. Rev., 45, 124 ; 1934 ${ }^{2}$ G. Herzberg, F. Patat, and J. W. T. Spinks, NATURE, 133, 951 June $23,1934$.

${ }^{3}$ C. A. Bradiey and A. McKellar, Phys. Rev., 46, 236; 1934

$4 \mathrm{G}$. Glocker and H. M.

${ }_{5} \mathrm{R}$. Mecke, $Z$. phys. Chem. B, 17, 1 ,

R. Mecke, Z. phys. Chem., B, 17, 1; 1932. 1934

D. M. Dennison, Rev. Mod. Phys., 3, 280; 1931.

\section{Diffusion of Heavy into Light Water}

We have made measurements of the diffusion coefficient of heavy water $(0 \cdot 5-3.0 \mathrm{~mol}$ per cent) in aqueous solutions. The value provisionally obtained is about $9 \times 10^{-4} \mathrm{~cm} .^{2} / \mathrm{sec}$. at $15^{\circ} \mathrm{C}$. Since this is appreciably greater than is to be expected from the mass diffusion of water molecules (the largest recorded diffusion coefficient, namely, that of $\mathrm{H}_{2}$ in $\mathrm{H}_{2} \mathrm{O}$, is about $4 \times 10^{-5} \mathrm{~cm} .{ }^{2} / \mathrm{sec}$.), it appears that an atomic interchange, such as has been suggested by Bernal and Fowler ${ }^{1}$ to account for the abnormal electrolytic mobility of the hydrogen and hydroxyl ions, is involved.

We hope to improve the accuracy of the method, and to determine the temperature coefficient.

$\begin{array}{ll}\text { King's Buildings, } & \text { W. J. C. OrR. } \\ \text { West Mains Road, } & \text { D. W. Thomson. } \\ \text { Edinburgh. } & \\ \text { J. Chem. Phys., 1, 515; 1933. } & \end{array}$

\section{Dielectric Potentials of Physiologically Active Substances}

Some physiologically active substances change the surface tension very little and are probably adsorbed at tissue interfaces as they exhibit an action. It seems possible to explain their adsorption and action by supposing that they change the electrical potential on the interface of different dielectrics, influencing but little the surface tension, which is taken into consideration by $W$. Gibbs in his well-known equation.

Measurements made in this laboratory on the potential at the interface active substance solution air with the aid of a Lindemann electrometer and a special modification of Kenrick's method gave the following preliminary results :

\begin{tabular}{|c|c|c|}
\hline Substance & Solution & Potential \\
\hline Quinine & $\begin{array}{l}M / 100 \text { quinine sulphate } \\
\text { M/100 quinine bihydrochloride }\end{array}$ & $\begin{array}{l}430 \mathrm{mv} \text {. } \\
300\end{array}$ \\
\hline Cin & Saturated solution of the base & $140 "$ \\
\hline dine & Saturated solution of the base & 10 \\
\hline & $\begin{array}{l}\text { 1.49 } \mathrm{gm} \text {. hydrochloride to one } \\
\text { litre of solution }\end{array}$ & 0 \\
\hline
\end{tabular}

Only a few of the measurements are given here. A full account will be published elsewhere in the near future. The potentials exhibited are very great at low concentrations compared with the known potentials of other substances measured by Kenrick and Frumkin. The potential changes with the hydrogen ion concentration. This may be explained by the influence of the ions on the structure and dissociation of the alkaloids. The dextro-and lævorotatory isomers of the same substance show different potentials.
Some physiologically active substances give no potential on the interface solution - air (in vivo, for example, the lung), but they give potentials on the interface water solution - solution of greater dielectric constant. Such dielectric constants are known in the living organism ; for example, substance of the brain, nerves and the surrounding solution.

The potentials seem to explain a vast field of physiological action and they deserve a special name. I propose the name 'dielectric potential' in distinction from the potentials met with on the interface conductor - solution, as in the elements of electrochemical cells.

Institute of Physical Chemistry

B. KAMIENSKI. and Electrochemistry, Jagellonian University, Cracow.

Oct. 14.

\section{Pit-Head Generation of Electric Power}

The analysis of my address at the Aberdeen meeting of the British Association contributed by a correspondent to NATURE of October 13 emphasises too strongly the part dealing with pit-head stations. My main theme was that the selling price of electricity was approaching a figure below which the demand would greatly increase, and only by this increase could the heavy cost of distribution be materially reduced. In order to start this increase in the demand the use of pit-head stations and the adaptation of industrial steam were advocated, and it was claimed that the existence of the Grid afforded facilities for bringing in these sources of supply, which formerly were difficult to use. A reduction in local rates was put forward as an additional help to this end, not as an argument in favour of pit-head stations.

The condensing water difficulty is always brought up against pit-head stations, and is usually overstated. Nor is your correspondent an exception. $\mathrm{He}$ quotes the Battersea station as having a thermal efficiency of above 26 per cent, using river water, against Hams Hall at Birmingham with $23 \cdot 3$ per cent using cooling towers; but he fails to take into account the facts that the Hams Hall machines are $30,000 \mathrm{kw}$. and work at $350 \mathrm{lb}$. steam pressure, while the Battersea machines are $67,000 \mathrm{kw}$. working at $600 \mathrm{lb}$. These two conditions alone would account for nearly all the difference in efficiency. Moreover, Hams Hall works at the low load factor of 0.32 , which lowers its efficiency. My statement that "the gain in efficiency due to the high vacuum is often exaggerated by failure to apply comparable conditions", was not unjustified.

Your correspondent also gives alarmist figures about the enormous loss of cooling water by evaporation. This is now slightly less than the amount of steam condensed, and in a $100,000 \mathrm{kw}$. station, working at a load factor of $0 \cdot 4$, it amounts, on the average, to a stream of water one foot wide and one foot deep flowing at the slow rate of a little more than one mile an hour. Few mines are so fortunate as to have less water to pump than this.

Increased distance of distribution is another objection, but this is now a very small matter if the distance is moderate. It is much cheaper to transmit electricity than coal. Moreover, the presence of a very large station in an urban area is becoming recognised as undesirable, and the concentration of industry in a few large centres no less so. It is hoped 